The Growth of the Body and Organs in Albino Rats Fed With a Lipoid-Free Ration

\title{
SHINKISHI HATAI
}

The $\|$ istar Institute of Anatomy and Biology

Reprinted from The Avatomical Recond, Vol.9, No. 1, January, 1915 



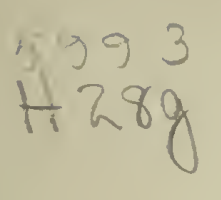

Reprinted from The Anatomical Recond, Vol. 9, No. 1

January, 1915

\title{
THE GROWTH OF THE BODY AND ORGANS IN ALBINO RATS FED WITH A LIPOID-FREE RATION
}

\author{
SHINKISHI HATAI \\ The Wistar Institute of Anatomy and Biology
}

Nearly seven years ago the writer attempted to raise stunted albino rats with the hope that a forced retardation of growth would induce some disturbance in the firm relation whichor$\leftarrow$ mally exists between the weight of the body and of the aentral N nervous system. The stunted rats were produced by feeding - them with a minimum amount of nitrogenous food. It was - found, however, that in this instance the artificial stunting did $\approx$ not modify the weight relation between the body and the central nervous system (Hatai '08). Although it was highly desirable to pursue this investigation further, yet on account of inconstancy and uncertainty of the outcome in raising stunted rats by the method employed, the investigation was postponed.

In 1911 Professors Osborne and Mendel published a series of remarkable papers in which the results of maintenance experiments by means of various isolated proteins were fully described. According to these investigators, albino rats about one-third grown can maintain their body weight for a considerable period without revealing any sign of nutritional or physical deterioration. This satisfactory and constant procedure for producing undersized rats renewed my interest in the problem mentioned.

During the past two years I have been so fortunate as to receive a number of stunted rats with their controls for examination. These came through the courtesy of Dr. McCollum, who raised the rats by feeding them with a 'lipoid-free ration.' These rats fall into two series: the series of 1913 and the series of 1914. The present paper contains the results of the anatomical examination of these interesting rats, and I take this

THE ANATOMICAL RECOBD, VOL. 9 , YO. 1

JANEARY, 1915 
opportunity to thank Dr. MeCollum for his courtesy in putting these animals at my disposal.

The rats used were from those bred in the colony at The Wistar Institute in Philadelphia and sent to the University of Wisconsin. In each case rats belonging to the same litter were divided by Dr. McCollum into two lots with nearly identical body weights. The one lot was used for control and received the normal mixed ration, while the other lot, which was used for the experiment, received a specially prepared diet. As to the dietary formula, the following statements were kindly furnished by Dr. McCollum: The ration of the experimented rats which received the lipoid-free food was as follows:

Casein...........18 per cent

Lactose..........20 per cent

The salts were as stated below:

\begin{tabular}{|c|c|c|}
\hline \multirow{2}{*}{ Salt mixture } & \multicolumn{2}{|c|}{ Per 100 grams of ration } \\
\hline & & \\
\hline $\mathrm{NaCl}$. & 0.808 & 0.168 \\
\hline $\mathrm{MgSO}_{4}$ (anhydrous)... & 0.264 & 0.264 \\
\hline $\mathrm{NaII}_{2} \mathrm{PO}_{4} \mathrm{H}_{2} \mathrm{O} \ldots \ldots \ldots$ & 0.336 & 0.336 \\
\hline $\mathrm{K}_{2} \mathrm{HPO}_{4}$ & 0.936 & 0.964 \\
\hline $\mathrm{CaH}_{4}(\mathrm{PO})_{2} \mathrm{H}_{2} \mathrm{O}$. . & 0.528 & 0.528 \\
\hline $\mathrm{Fe}$ citrate $\ldots \ldots \ldots \ldots \ldots \ldots \ldots \ldots \ldots$ & 0.096 & 0.096 \\
\hline Ca lactate.......... & 2.000 & 1.300 \\
\hline
\end{tabular}

The salt mixtures no. 174 and no. 185 were given at different periods in the case of both series.

At the end of the experiment these rats were shipped back to The Wistar Institute for the anatomical examination, where the writer determined the weights of the following organs: Brain and spinal cord, heart, lungs, kidneys, liver, spleen, alimentary tract, testes and ovaries, suprarenals, thymus, thyroid, hypophysis and eyeballs. Some of these organs were preserved for further histological examination. Besides the organs mentioned, the bones also were examined.

Although the methods employed in determining the relative amount of alteration in the various organs of the experimented rats, and also the technique for the preparation of the bones and separation of the encephalon into the four parts can be found 
in my papers recently published (Hatai '13 and '14), I shall briefly restate the essential points.

The encephalon was divided. into four parts in the following way:

1. Olfactory bulbs. The protruding portions of the olfactory tract with bulbs were cut from the rest of the encephalon by section of the tract just caudad to the bulb.

2. Cerebrum. The cerebrum is separated from the stem by a cut passing just in front of the dorsal edge of the anterior colliculi and just caudad to the corpus mammillare on the ventral surface.

3. Cerebellum. The cerebellum is separated by severing the peduncles.

4. Stem. The structure which is left after removal of these three parts mentioned above, is called the stem.

The bones were prepared as follows: The bones are freed from the main bulk of muscles and placed in a hot aqueous solution of 2 per cent 'gold dust washing powder.' After maceration for several hours at nearly $90^{\circ} \mathrm{C}$., the remaining soft parts are removed. The bones thus prepared are gently wiped with blotting paper and are weighed. This gives the 'fresh weight.' These weighed bones are then dried at $95^{\circ} \mathrm{C}$. for one week and the amount of moisture determined from the weight of the dried residue.

In order to determine the amount of modification following the experimental ration, we have employed our usual method of comparing the observed values with those found in a series of reference tables that have been compiled in this laboratory. These tables present for normal rats adequate data on all the organs and characters under consideration and in each case the graph representing the table can be expressed by a mathematical formula (Hatai '13; Hatai '14).

In making the comparison between the observed values and those in the tables - the body length is always used as the basal measurement and the weight of the body or organs as observed compared with the corresponding values given in the reference tables. In this manner comparison is made not only for the 
experimented rats but also for those used as controls. The departures of the observed values from those in the tables having been observed in each case - the difference between that found for the experimented animals and that for the controls is obtained and this figure is used to indicate the amount by which the experimented animals have been modified.

Two examples will serve to illustrate this procedure. They are taken from table $3-\mathrm{C}$, normal males, 1914 series: (1) On the 'mixed ration' the average tail length for the three rats is . $172 \mathrm{~mm}$., for the given body length, $196 \mathrm{~mm}$. We expect from the reference tables a tail length of $165 \mathrm{~mm}$. The observed value is therefore plus 4.2 per cent. The two rats on the "lipoid-free diet and egg fat" give a tail length of $151 \mathrm{~mm}$. for a body length of $168 \mathrm{~mm}$. From the reference tables we should expect a tail length of $139 \mathrm{~mm}$. The observed value for the tail length of the experimented group is therefore plus 8.6 per cent. The difference between these two percentage shows the tail length in the experimented group to be $8.6-4.2$, or 4.4 per cent greater than that of the controls. This is the value given in table 3. (2) Taking the brain weights for the groups just used we find by following the method employed above for the tail length, that the group on the "mixed ration" has a brain weight 4.8 per cent below the reference table value, while the group on the "lipoid-free ration plus egg-fat" has a brain weight which is 6.4 per cent deficient. Thus the brain weight in the experimented group is -6.4 less -4.8 or 1.6 per cent lower than in the controls. This is the value entered in table 2. All the percentage differences in the accompanying tables have been obtained in a manner similar to that illustrated by the two examples just given.

The only modification in procedure to which attention need be drawn is in the cases where the data from two series, 1913 and 1914, have been combined. In those cases the percentage deviation which is given in the table is the mean of the deviations for each serjes computed separately. 


\section{GROWTH OF BODY IN WEIGHT}

The modifications of the growth of the body in weight due to the lipoid-free ration are shown in tables 1 and 2. Table 1 refers to the growth of the albino rats belonging to the 1913 series, while table 2 refers to the growth of the 1914 series. We note in both tables that the rats fed with the mixed ration made nearly normal growth in respect to their ages (see Donaldson '06). The spring

TABLE 1

Showing the weight of the body as modified by the lipoid-free ration compared with that of the rats raised on the mixed ration (1913 series)

\begin{tabular}{|c|c|c|c|c|c|}
\hline & \multirow{2}{*}{ DATE } & \multicolumn{2}{|c|}{ MALES } & \multicolumn{2}{|c|}{ FEMALES } \\
\hline & & $\begin{array}{l}\text { Mixed } \\
\text { ration (3) }\end{array}$ & $\begin{array}{l}\text { Lipoid-free } \\
\text { ration }(4)\end{array}$ & $\begin{array}{c}\text { Mixed } \\
\text { ration (4) }\end{array}$ & $\begin{array}{l}\text { Lipoid-free } \\
\text { ration (5) }\end{array}$ \\
\hline \multirow{2}{*}{$\begin{array}{r}1913 \\
\text { April }\end{array}$} & 16 & 047 & 038 & 850 & 762 \\
\hline & $30 \ldots$ & 129.7 & 122.7 & 112.0 & 92.4 \\
\hline \multirow[t]{4}{*}{ May } & $7 \ldots \ldots \ldots$ & 137.7 & 127.8 & 125.7 & 98.6 \\
\hline & $14 \ldots$ & 153.7 & 134.8 & 146.7 & 108.4 \\
\hline & $21 \ldots$ & 149.3 & 136.5 & litters & 107.4 \\
\hline & $28 \ldots$ & 159.7 & 139.0 & " $"$ & 108.4 \\
\hline \multirow[t]{4}{*}{ June } & $4 \ldots$ & 166.3 & 140.7 & " $"$ & 108.4 \\
\hline & $11 \ldots$ & 173.3 & 131.5 & 129.0 & 103.8 \\
\hline & $23 \ldots$ & 185.0 & 124.8 & 140.7 & 107.8 \\
\hline & 30. & 196.7 & 134.2 & 143.3 & 109.0 \\
\hline \multirow[t]{4}{*}{ July } & 7. & 209.7 & 139.7 & 151.0 & 111.6 \\
\hline & $14 \ldots \ldots \ldots$ & 223.3 & 143.2 & 156.7 & 111.0 \\
\hline & $21 \ldots \ldots \ldots \ldots$ & 222.7 & 149.2 & 161.0 & 107.2 \\
\hline & $28 \ldots \ldots \ldots \ldots$ & 229.0 & 151.0 & 166.0 & 111.8 \\
\hline August & $15 \ldots \ldots \ldots \ldots \ldots$ & 243.3 & 155.0 & 167.7 & 118.6 \\
\hline September & $-1 \ldots \ldots \ldots \ldots \ldots$ & 249.7 & 153.5 & 172.7 & 125.2 \\
\hline
\end{tabular}

rats in 1913 made much better growth than the autumn rats in 1914. On the other hand, the experimented rats in both series made a noticeably poor growth when contrasted with the controls. In the 1913 series we notice that the experimented rats made continuous and steady growth throughout the period of experimentation, although the total amount of growth in weight was very slight. Curiously enough the experimented rats belonging to 1914 made a still smaller growth, and indeed in some cases the final body weight is no higher than the body weight at the begin- 


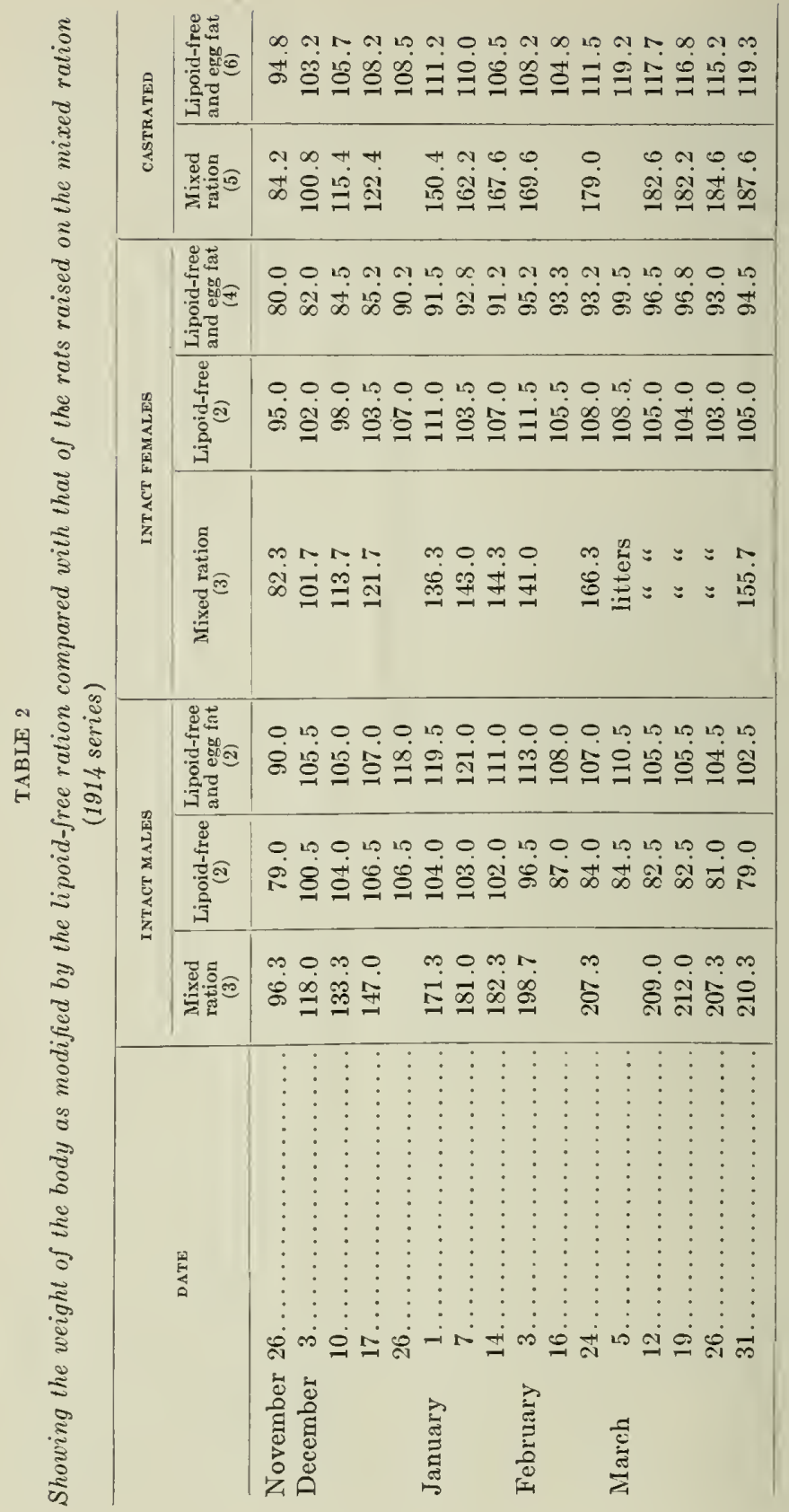


ning of the experiment. This difference in growth in the two series may probably be due to the different physiological condition of the rats in these two series, combined with slight differences in the preparation of the ration. One point is clear, however: that the rats cannot continue the normal rate of growth on the lipoid-free ration in combination with the salt mixture which was used.

In table 2 we have also the data on the growth of the body of the albino rats which were fed first with the lipoid-free ration and later with the same ration to which a minute quantity of the egg-fat had been added. For convenience, these last mentioned rats will be designated simply as 'egg-fat series.'

It was found by McCollum and Davis ('13) that the rats whose body growth had ceased for a long period as the result of the lipoid-free ration, could be made to grow by the addition of a minute quantity of the extract of egg to the experimental ration. In order to see whether or not the rats thus treated would show any modifications other than those shown by the rats fed with the simple experimental ration, a small series was carried on. As will be seen from table 2, the 1914 rats given the extract of egg did not show the improvement in the growth of the body which was to be anticipated. ${ }^{1}$ Thus the growth of the body is nearly identical in both the lipoid-free series and in the egg-fat series. Why in the present experiment the egg-fat series did not show a noticeable improvement in the growth of the body is not clear. However, from the fact that the control rats belonging to the 1914 series did not make satisfactory growth when contrasted with the 1913 series, we conclude that the failure to grow was

1 "Our experience in feeding synthetic rations in this laboratory has convinced us that there exists a great variation in the vitality of individual rats as indicated by their ability to grow on such rations. It is unfortunate that practically all of the animals employed in the work herc reported were not sufficiently vigorous to grow for a time in a nearly normal manner on the experimental ration, or to respond by a period of active growth when the ration was supplemented with egg yolk fats. Wc have individual rats in our colony at the present time which have been on the diet employed in the lipoid-free period with egg yolk fats added, during more than six hundred days, and which compare favorably with our stock rats in size and well-being."-E. V. McCollum. 
probably due to a peculiarity of the rats rather than a peculiarity of the experimental ration.

Osborne and Mendel ('12) obtained normal growth of the rats with the ration from which the lipoid had been almost entirely removed. They carried the experiment for a considerable length of time by beginning with albino rats slightly over 30 days in age. In one series the experiment lasted for nearly 160 days. In every instance, so far as one can judge from the graphs, the body weight of the experimented rats was nearly identical with that of the control rats, while McCollum and Davis' rats, fed with the lipoid-free ration, did not grow at any period to the size of the controls (McCollum and Davis '13; see also present series).

This difference in growth between the rats of Osborne and Mendel, on the one hand, and those of McCollum and Davis on the other, was undoubtedly due to the nature of the inorganic salts and some extracts still contained in the food. The Osborne and Mendel rats received the inorganic salts from protein-free milk, while those of McCollum and Davis received the salts which were a laboratory mixture of pure chemicals. In reference to the varying effects of different salt mixtures McCollum and Davis state ('13) that

"Young rats have been found to be very sensitive to variations in the character of the salt mixtures supplied, but with certain mixtures we have been able to obtain practically normal growth for periods varying from 70 to 120 days. Beyond that time little or no increase in body weight can be induced with such rations. The rats may remain in an apparently good nutritional condition on those rations for many weeks after growth ceases."

\section{ANATOMICAL ANALYSIS}

We now wish to present the results of the anatomical examination of these interesting rats reared by McCollum at the University of Wisconsin.

Although the growth rate was dissimilar in the two consecutive years, nevertheless it was found that the alterations shown by the various characters are nearly identical in the two series of exper:ments, and on account of this uniformity in the results, as well as to avoid unnecessary complication by presenting the 
two series of data separately, I have combined the results. Consequently, unless otherwise stated, the figures given in the tables represent the averages of the two sets of data belonging to the 1913 and the 1914 series combined.

\section{CENTRAL NERVOUS SYSTEM}

If the lipoid-free ration is able to produce any alterations in the lipoid content of the organs, the central nervous system would naturally be expected to indicate such effects, since the central nervous system of the albino rat at about 200 days of age normally contains some 60 per cent of lipoid in the dried residue (Koch '13). This lipoid content is certainly greater in the nervous system than in any other organ (Koch '11). The weights of the central nervous systems of the experimented and of the control rats are shown in table 3 (see also page 16). As will be seen from this table, the weight of the brain with respect to the body length is generally slightly smaller in both the lipoidfree and egg-fat series. Only one exception is found in the female rats (B) fed with the lipoid-free ration in which the experimented rats show a slight over weight of 0.7 per cent. This slight increase is probably due to the abnormally small brain weight of the control rats, thus raising the relative weight of the central nervous system of the experimented rats. Indeed the normal brain weight of the female rats corresponding to the body length of $189 \mathrm{~mm}$. should be 1.80 grams as against the observed weight of 1.73 grams, i.e., the observed weight of the control is nearly 4 per cent less than the normal brain weight. Without making any correction, however, we find on the average that the experimented rats show about 2 per cent less brain weight than the controls.

Similarly we find a reduction of 2.1 per cent in the weight of the spinal cord when compared with that of the control rats. This reduction of 2 per cent in weight in both the brain and spinal cord is somewhat greater than what we might expect from the normal fluctuation, nevertheless it is certainly far smaller than one might anticipate from the nature of the experiment. It seems reasonable, therefore, to conclude that the central nervous 
SHINKISHI HATAI

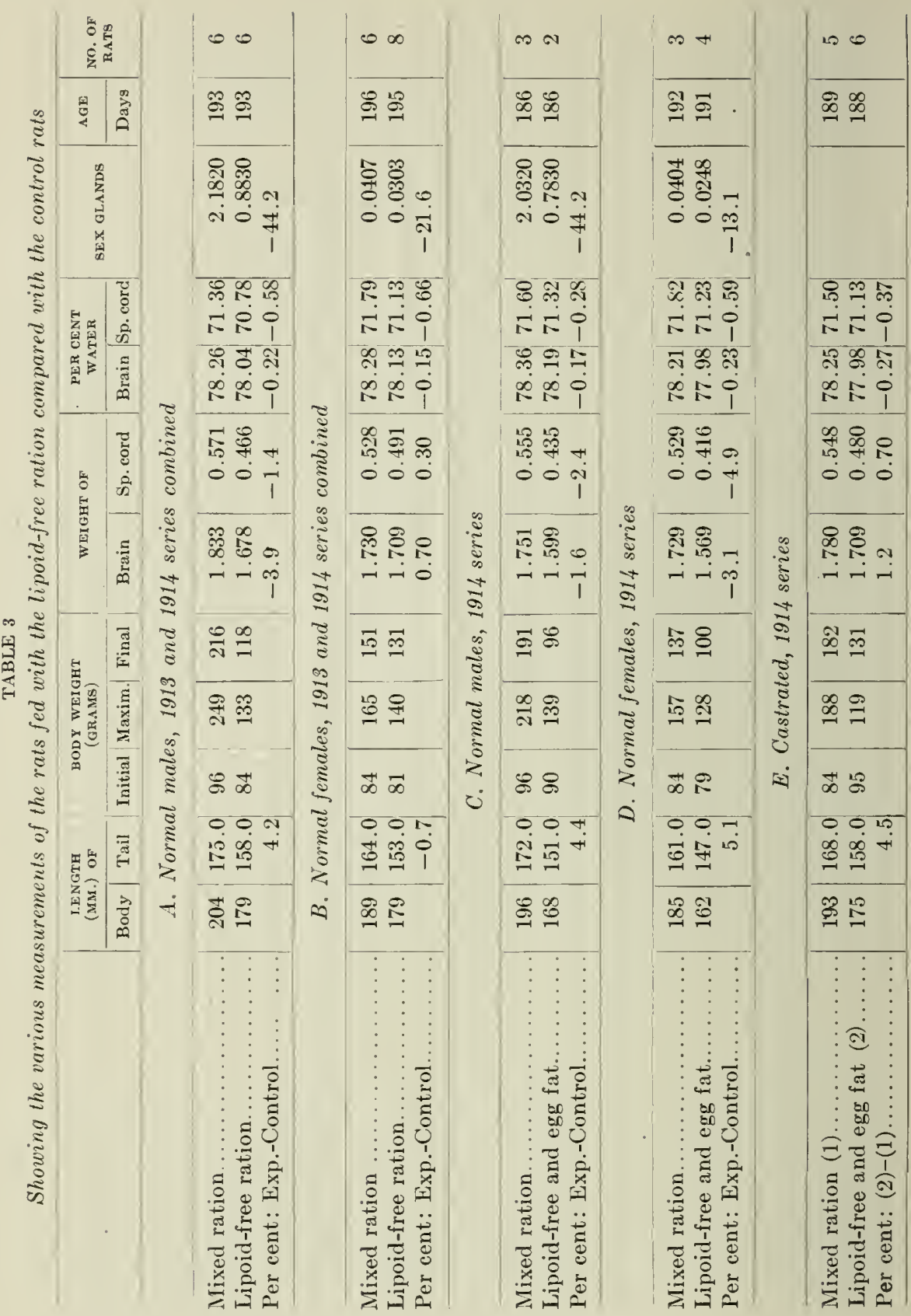


system is adequately supplied with the necessary amount of the lipoids from the body and this fact in turn leads us to assume that the body has the ability to synthesize the lipoids from the non-lipoid materials. McCollum ('12) has demonstrated that the phosphorus needed by the animal for phosphatid formation can be drawn from inorganic phosphates, and that phosphatids can be synthesized anew in the animal body. Further investigation of McCollum ('12) indicates that certain complex lipoids of the lecithin type can be synthesized in large amounts by birds.

The percentage of water found in the central nervous system indicates also that the chemical composition has not been noticeably altered since the difference between the control and experimented rats is only 0.2 per cent in the brain and 0.5 per cent in the spinal cord; both in favor of the controls. It is to be noted, however, that a small reduction appears in all the experimented series, thus indicating a strong tendency to a slight modification.

To determine whether or not the reduction of 2 per cent in the weight of the central nervous system was mainly caused by the alteration in the white substance, in which the lipoids are predominant, the brain was divided into four parts and the weights and water content of those parts were found separately. The results of the investigation are shown in table 4 . We notice from the table that although the percentage of water tends to be smaller in the experimented rats in all four parts, nevertheless the greatest relative reduction appears in the olfactory bulbs, the cerebellum comes next and the cerebrum and stem come in the order named. Thus the stem where the lipoid constituent is greatest is least modified and the olfactory bulbs and cerebellum, where the lipoid constituent is least, are most affected. From this we infer that the gray substance is most affected, and the white substance, in which one might anticipate the largest alteration, is least modified.

This fact of greater change of the gray matter is interesting, since it is found that during partial starvation with non-nitrogenous food for three weeks, the total brain weight shows a reduction of 5 per cent (Hatai '04) but the amount of myelin, as can be seen from the normality in the amount of alcohol and 


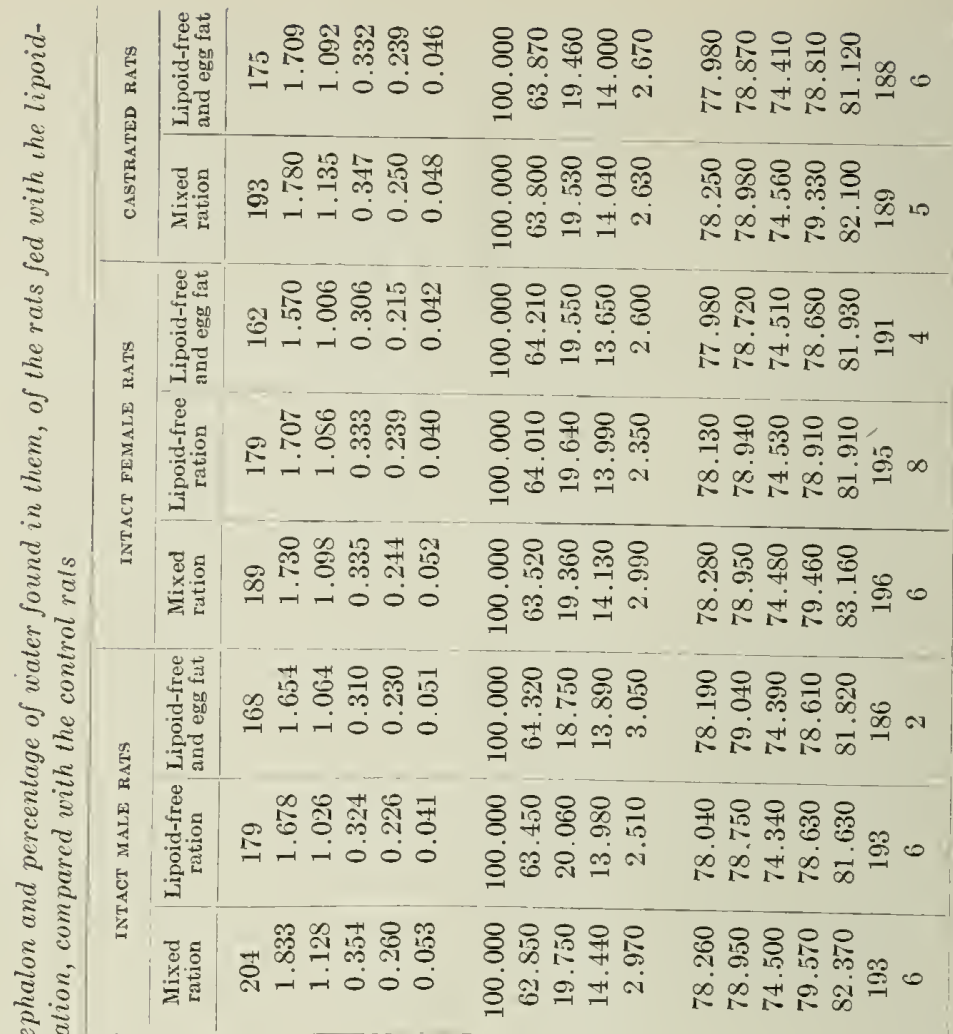


ether extract as well as from the Weigert preparations, is not altered (Donaldson '11). We conclude therefore that the absence of lipoids from the ration does not affect the amount of the lipoids in the central nervous system, but on the contrary, the gray substance is affected. This alteration of the gray substance is similar to the effect of partial starvation on the brain of the albino rat.

\section{SKELETAL SYSTEM}

The skeletal system is naturally looked on as another structure which might show some alteration owing to the use of the artificial mixture of the pure chemicals contained in the ration in place of the salts normally present. For this purpose the following bones were examined: femur, tibia and fibula, humerus, radius and ulna. The results of the investigation are given in table 5 . We note from this table that the ratio between body length and bone length and the ratio between body weight and bone weight are not altered. However, the water content found in these bones shows a distinct alteration in the experimented rats. The difference amounts to as much as 5.5 per cent in the case of the lipoid-free ration and 5.3 per cent in the case of the egg fat series; both in favor of the experimented rats. This difference of over 5 per cent is far greater than the usual incidental fluctuations. Furthermore, its constancy in direction in all these cases indicates that the chemical composition of the bones must be affected as the result of the experimental ration.

\section{SEX GLANDS}

The alterations thus far recorded are all of small magnitude, but we now come to the consideration of the one very obvious alteration. This is manifested by the testes and ovaries.

\section{TESTES}

We notice from table 3 that the experimented male has considerably smaller testes than the control. The difference amounts to as much as 44 per cent against the experimented. We notice also that the initial body weight of the experimented male rat 


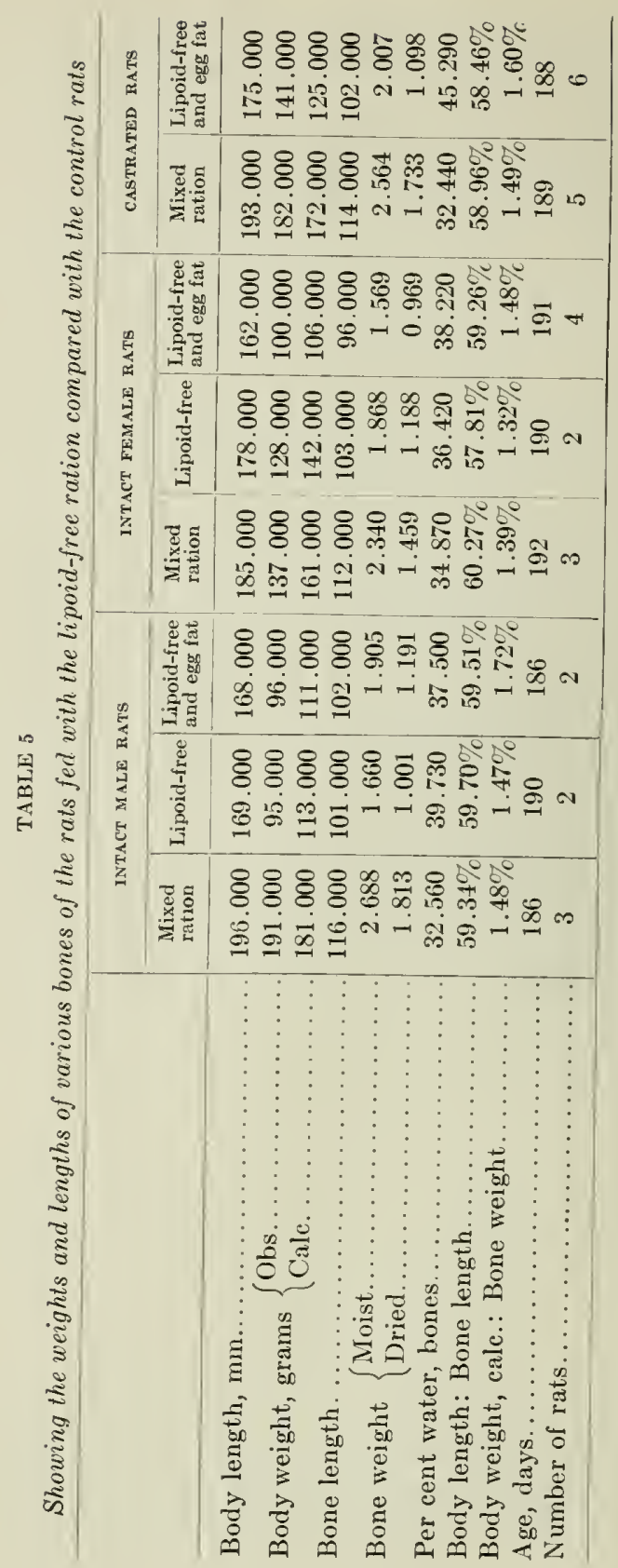


was 87 grams; this body weight calls for nearly 1.09 grams of testes, while the observed final weight is but 0.83 grams, thus showing a difference of nearly 23 per cent. We conclude therefore that the testes not only failed to grow during nearly six months of the special diet, but that there is a clear indication of an actual loss in weight.

\section{OVARIES}

In the case of the ovaries the difference between the controls and experimented is less than one-half of that found in the case of testes. The difference amounts to 17.4 per cent against the experimented. The initial body weight of the female rat was 80 grams; this body weight calls for nearly 0.015 grams of ovaries, while the observed final weight is 0.028 grams, thus showing an increment of more than 80 per cent during the experimental period of nearly six months. Thus it is clear that although the weight of the ovaries was 17 per cent smaller than that of the controls, nevertheless the ovaries of the experimented rats made steady growth, and indeed the final weight of the ovaries was nearly double the initial weight. The functional normality of the ovaries in the lipoid-free series is demonstrated by the fact that some of the females raised on the lipoid-free ration produced litters (McCollum and Davis '13).

\section{EFFECT OF LIPOID-FREE RATION ON CASTRATED MALE RATS}

The reduction of the testes in weight as the result of the experimental ration (1913 series) suggested that the same experimental ration when given to castrated male rats might produce a different alteration. To determine this point a series of castrated rats was sent to Dr. McCollum. Five of these castrated rats were fed with a mixed ration and six others were fed with the lipoid-free ration, to which latter a small amount of the egg-fat was added occasionally. The results of the investigation are given in tables $2,3,4$ and 5 . As is seen from table 2 , the growth of the body in weight in castrates fed with the lipoid-free ration is similar to that of the intact rats fed in the same way. Thus castration, plus the lipoid-free ration, does not produce any other alterations, the testis excepted, than those shown by the intact rats fed in the same way. 
We further note from tables 3 (E) and 4 that the central nervous system of the castrates fed with the experimental ration is not different from that of the intact rats fed in the same way Thus it is clear that the effect of the ration is not modified by castration. This conclusion applies also to the ratio between body length and bone length and the ratio between body weight and bone weight. The only difference is found in the percentage of water in bones of those castrates fed with lipoid-free ration.

We note that the difference in the water content of the bones between the castrates fed with the mixed ration and the castrates fed with the experimental ration, amounts to 13 per cent, which is much more than the difference between the intact rats on a mixed ration and those on the experimental ration. This greater difference of water content is found also in all individual cases. We conclude, therefore, that castration followed by the lipoid-free ration produces no further alteration than is found in the non-castrated rats fed with the same experimental ration, except in the water content in the bones. No explanation is possible for this singular result until further experiments have been made.

\section{THE VISCERAL ORGANS AND DUCTLESS GLANDS}

As has already been stated, the visceral organs and ductless glands, together with the eyeballs of these rats, were also examined. However, in view of the greater variability of these organs as well as the relatively small number of rats examined, I have decided not to attempt at this moment to interpret the alterations recorded by these organs. Nevertheless, for the reader who may wish to know the weight relations between the controls and the experimented rats shown by these organs, table 6 is given, where the results of the investigation are presented.

It may be important to add one word concerning the weight of the lungs. As will be seen from table 6 , the weights of the lungs belonging to the experimented rats are always considerably smaller than those of the controls. This means that the lungs of the experimented rats were in a healthy condition and that the greater weights found in the controls were due not to sound lungs of larger size, but to a diseased condition. This fact must 
be considered when interpreting the weight relations given by various other organs whose weights vary with the condition of the lungs (Hatai '13).

\section{CONCLUSIONS}

1. The lipoid-free ration diminishes the normal rate of the growth of the body.

2. The weight of the central nervous system shows a reduction of about 2 per cent as the result of the expermental ration. The percentage of water found in the central nervous system shows a very slight diminution.

3. The different parts of the encephalon are differently altered. In general, the parts where the gray substance is predominant are more affected than the parts where the white substance is predominant.

4. The weight and length of the longer bones with respect to body weight and body length are not modified. The percentage of water found in these bones, however, is constantly greater ( 5 per cent) in the experimented rats. This indicates that the chemical composition of the skeletal system has been somewhat altered.

5. The testes of the experimented rats showed not only a deficiency of 44 per cent as a result of six months of the lipoidfree diet, but there is a clear indication of actual loss in weight (23 per cent).

6. The ovaries of the experimented rats were smaller in weight by 17.4 per cent but no loss of the gland has occurred and growth was continuous.

7. The reactions shown by the lipoid-free ration and egg fat series are similar to those produced by partial starvation, especially with respect to the responses by the central nervous system and by the sex glands.

8. Although the lipoid-free ration causes a marked atrophy of the testes, yet in castrates on the lipoid-free ration no special alteration occurs which can be referred to castration, save the diminution of the solids in the bones.

9. Two incidental observations call for comment: (a) The loss of solids in the bones of the rats receiving a lipoid-free diet is of interest owing to the possible use of the phosphorus of the 


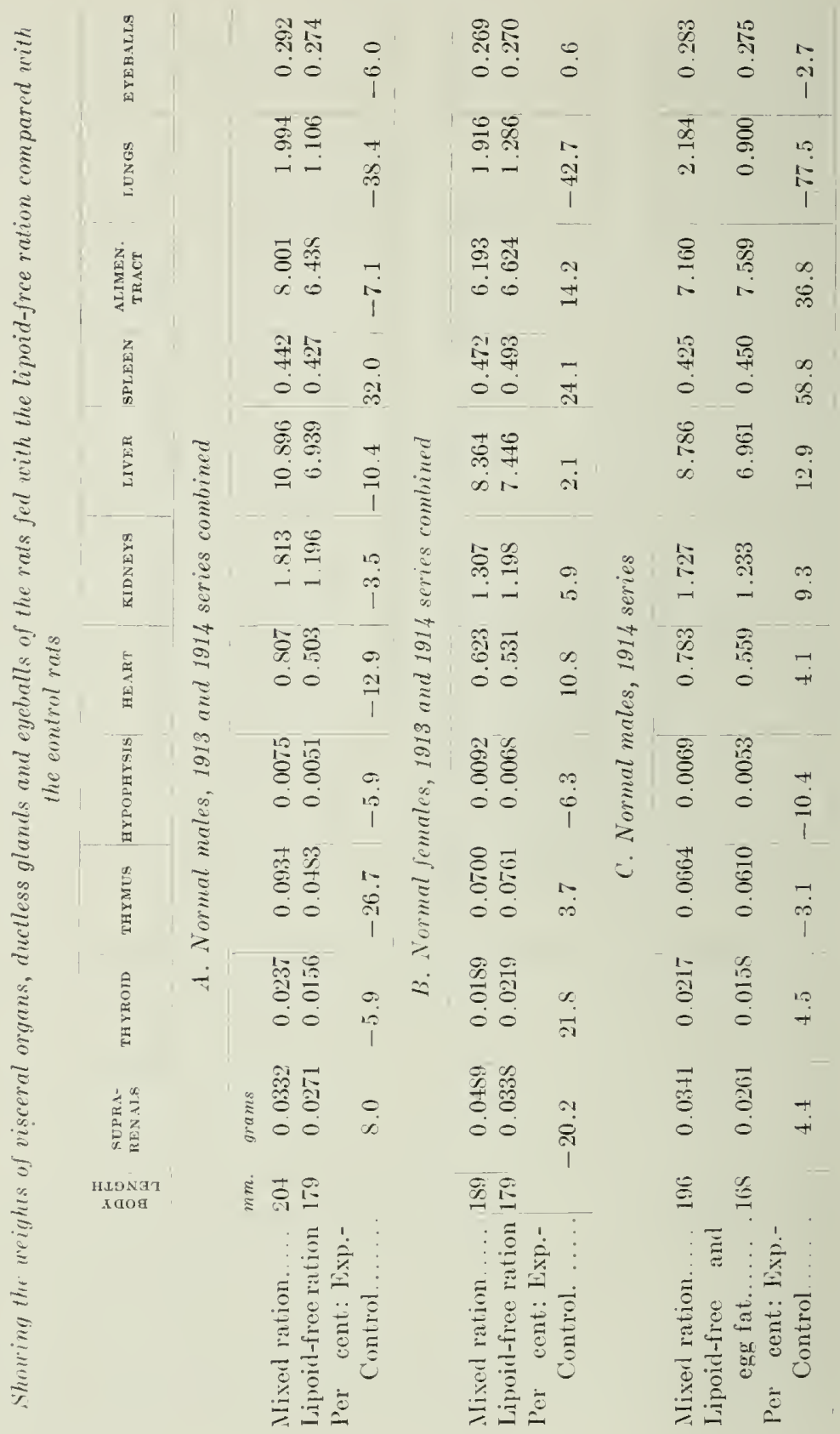




$$
\text { GROWTH OF BODY AND ORGANS }
$$

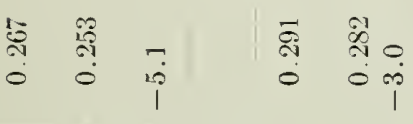

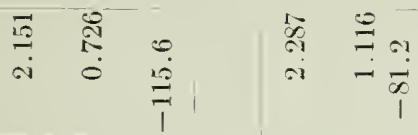

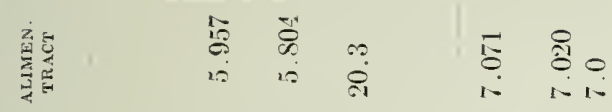

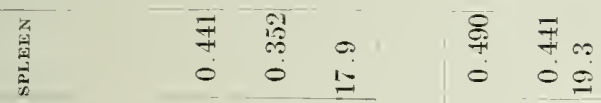

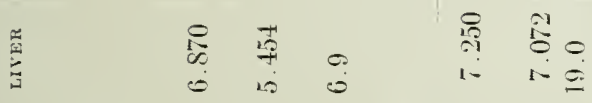

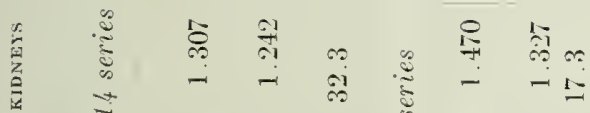

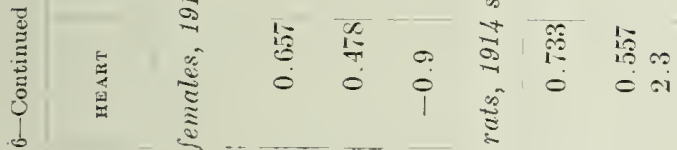

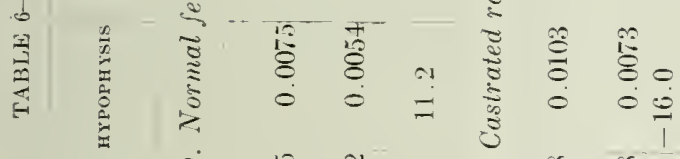

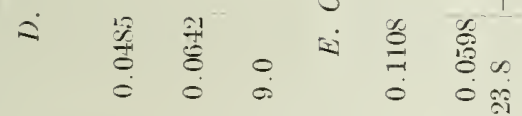

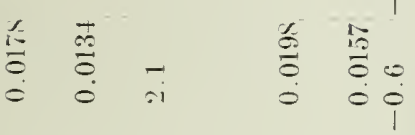

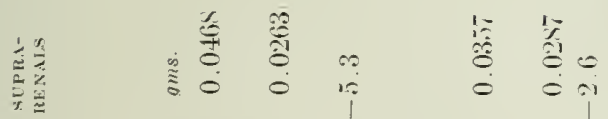

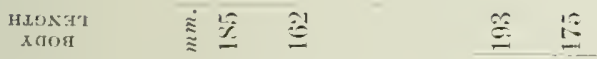

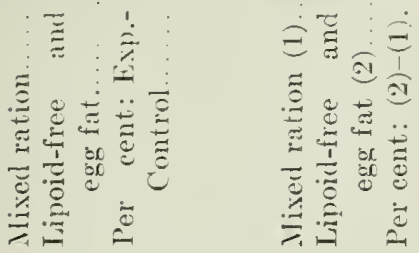


bone in the formation of lipoids. (b) On the lipoid-free diet, as well as in various forms of underfeeding, and after longcontinued exercise, the rats become remarkably resistant to the lung infection which appears in the controls.

LITERATIRE CITED

Donaldson, H. II. 1906 A comparison of the white rat with man in respect to the grow th of the entire body. Boas Anniversary Volume, New York. 1911 The effect of underfeeling on the percentage of water, on the ether-alcohol extract and on medullation in the central nervous system of the albino rat. Jour. Comp. Neur., vol. 21, no. 2, pp. 139-145.

1911 a An interpretation of some differences in the percentage of water found in the central nervous system of the albino rat and due to conditions other than age. Jour. Comp. Neur., vol. 21, no. 2, pp. 161-176.

HATA1, S. 1904 The effect of partial starvation on the brain of the white rat. Amer. Jour. Physiol., vol. 12, no. 1, pp. 116-127.

1908 Preliminary note on the size and condition of the central nervous system in albino rats experimentally stunted. Jour. Comp. Neur., vol. 18, no. 2, pp. 151-155.

1913 On the weights of the abdominal and the thoracic viscera, the sex glands, ductless glands and the eyeballs of the albino rat (Mus norvegicus albinus) according to body weight. Am. Jour. Anat., vol. 15 , no. 1 , pp. 87-119.

1914 On the weight of the thymus gland of the albino rat (Mus norvegicus albinus) according to age. Am. Jour. Anat., vol. 16, no. 2, pp. 25̃1-257.

1915 The growth of organs in the albino rat as affected by gonadectomy. Jour. Exp. Zoöl., vol. 18, no. 1, pp. 1-68.

Косн, W. 1911 Recent sturlies on lipoids. Jour. Amer. Med. Assoc., vol. 56, pp. 799-801.

1913 Contributions to the chemical differentiation of the central nervous system. III. The chemical differentiation of the brain of the albino rat during growth. Jour. Biol. Chem., vol. 15, no. 3, pp. 423448.

McCollum, E. V., and Davis, Marguerite 1913 The necessity of certain lipins in the diet during growth. Jour. Biol. Chem., vol. 15, no. 1, pp. 167-175. 1914 Further observations on the physiological properties of the lipins of the egg yolk. Proc. Soc. Exp. Biol. and Med., vol. 11, no. 3, pp. $101-102$.

McCollom, E. V., Halpix, J. G., and Drescher, A. H. 1912 Synthesis of lecithin in the hen and the character of lecithins produced. Jour. Biol. Chem., vol. 13, no. 2, pp. 219-224.

Osborne, T. B., and MENDEL, L. B. 1911 Feeding experinents with isolated food substances. Carnegie Institution of Washington, Publication No. 156.

1912 Feeding experiments with fat-free food mixtures. Jour. Biol. Chem.. vol. 12 , no. 1, pp. 81-\$9. 



\section{THE ANATOMICAL RECORD}

VOLUME 9, NUMBER 1, JANTARY 20, 1915

\section{CONTENTS}

Shinkishi Hatai. The growth of the body and organs in albino rats fed with a lipoidfree ration...................................................... I FREDERICK S. HaMmetT. The source of the hydrochloric acid found in the stomach.. 21 Stropping machine for microtome knives (M. J. G.) Three figures............... 26 Daniel Davis. A simple apparatus for microscopic and macroscopic photography.

Three figures.................................................. 29 Journals Announcement............................................ 34

Proceedings of the American Association of Anatomists. Thirty-first session........ 35 Proceedings of the American Association of Anatcmists. Abstracts............ .. 45

Proceedings of the American Association of Anatomists. Demonstrations. . . . . . . . 138

List of officers and members......................................... 145 